\title{
Parallelism in Hemingway's Old Man and the Sea: Syntactic and Semantic Study
}

\author{
Prof. Riyadh T. K. Al-Ameedi (PhD) \\ Department of English, University of Babylon, College of Education for Human Sciences, Babylon, Iraq. Email: \\ hum.riyadh.tareq@uobablyon.edu.iq
}

\author{
Asst. Lect. Omar Osama Nashaat \\ Department of English, University of Babylon, College of Education for Human Sciences, Babylon, Iraq. Email: \\ oo8004880@gmail.com
}

\begin{abstract}
Parallelism are linked to the style of Ernest Hemingway's writings. They have an origin in the natural creativity of the writer. Through parallelism, writer's emotions, feelings, style, use, are manifested with a kind of vividness. The current paper attempts to identify stylistic elements in Ernest Hemingway's 'The Old Man and The Sea'. The paper attempts to focus on the syntactic and lexical elements, analyse them and figure out the writer's purposes behind using such elements in this kind of literary text. The paper consists of two parts: an introduction on stylistics and parallelism. The latter is the analysis of Hemingway's novel Old Man and The Sea and tackles the prominent parallel elements syntactically and semantically in an attempt to find out the purpose behind using such devices.
\end{abstract}

Keywords:

stylistics, parallelism, types of repetition, syntactic parallelism, lexical parallelism,

\section{Introduction}

Language of literature is not like everyday language in which the speaker is not interested in the aesthetic value of language. Wales (2001: 36) explains that literary language basically depends on deviation to deautomatize the message he wants to convey, in other words, to draw readers' attention to the language he uses consciously. This can be done be using certain stylistic devices such as parallelism, word choices, metaphor and other devices which violate the norms of normal language (Emmott \& Alexander 2014: 329). In literary language, the effect of aesthetic devices cannot be independent of the creative employment of linguistic code (Short \& Leech 2007:2). Accordingly, how does the aesthetic employment process of linguistic code create such aesthetic effect? And what makes some literary devices aesthetic?

The aesthetic function of literary works come to surface by Roman Jakobson's model entitled 'Model of Communication'. In 1960, Jakobson defines the aesthetic function of literary language as a way in which the reader concentrates on either the form of the message or the message itself (Jakobson 1960: 356). The function of literary language is directed from selection to combination. Waugh (1980: 64) stated that this kind of direction if the essential element in literary language. According to Jakobson 1960: 358), the idea of selection focuses on both similarity and contrast (the pragmatic element) while the idea of combination focuses on the organization of sequences (the syntagmatic element). Wales (2001: 304) clarifies that the aesthetic function takes place when the organization of literary language and meaning deviates from the norms of the normal language especially by the means of parallelism.

\section{Stylistics}

In any literary text, author's style is the most important feature which can be recognized easily within stylistics. In other words, stylistics is the branch of linguistics which studies styles' variations. Writers employ some stylistic devices to create a certain effect on readers. 
The word 'stylistics' is derived from the French word 'stylistique' which refers to the training course in philology (Burlak et al, 1996: 7). According to Widdowson (1975: 3), stylistics is an interdisciplinary field of which connects linguistics with literary criticism. Stylistics deals with literary texts from a linguistic perspective. Moreover, Chapman (1973: 11) regards stylistics as the scientific study of various styles of language. From another dimension, stylistics has been defined as a field within linguistics which focuses on different use of language especially in literature (Turner, 1973: 7). Stylistic devices are tools and sometimes so-called techniques employed by poets or writers in literature. Those tools add uniqueness to the novelty of language of the text.

\section{Parallelism and Literary Text}

Bloomfield (1976: 279) states that the different parts of a literary text form its grammar. This kind of grammar has integral parts which can interact together to contribute to the whole text. Wales (2001: 304) suggests that the function of integration achieved by parallel forms can work in all levels such as phonology, syntax and semantics. It can trigger in one's mind, what is parallelism? Crystal (2003: 466) says that it is the actual employment of a pair of constructions, words or sounds. Short (1996: 14) argues that parallelism is vital apparatus for literary language control. An example from T.S. Eliot's The Hollow Men:

- This is the dead land

This is the cactus land ...

According parallelism, these two lines have parallel structures which can be adopted to help the reader understanding the link between the two ideas. Mathews (2007: 286) suggests that parallelism is the aesthetic effect of linguistic units which have parallel structures. Rozakis (2003: 137) clarifies that parallelism is an equilibrium device to sentences as these parallel constructions are grammatically the same. While Malmkjær (2010: 520) states that parallelism is a phenomenon which gives the reader a great joy by noticing and exploring parallel structures at different levels; auditory, visual and so on. Rules of parallelism exist when the reader tries to figure out the lexical connection among parallel forms (Short 1996: 15). Parallelism comes in different forms, whether identical forms or different forms (Alakrash et.al.2020, Bustan\&Alakrash 2020).

According to Lotman (1977: 85), there are two kinds of combining; the first is the combination of identical elements and the second is the combination of diverse elements. Gregoriou (2009: 37) states that when parallel words exist in a literary text, whether they are parallel phonologically, syntactically or semantically, there seems to be a kind of similarities or differences among the lexical links of these words. The term Parallelism has an origin in Robert Lowth's writings dated to (1778) on parallelism in biblical Hebrew. Jakobson (1966: 399) explains that G. M. Hopkins made a full analysis on syntactic parallelism in the $19^{\text {th }}$ century. He says that the arrangement of literary text is made of continuous repetition.

Parallelism makes a certain harmony in two sentences either by synonymy or antithetic thoughts or synthetic (Guillen 1987: 507, Elaf \& Hussien 2020).

Parallelism indicates the idea of equivalence. According to Leech (1977: 67), parallelism in the equivalence in the parallel ingredients which represents similarities and differences. Parallelism is connected somehow to logic. Gee (1999:147) states that parallelism is the device which is used to connect text element in a logical hierarchical way. Paragraphs in a text, sentences in a paragraph and clauses in a sentence. Parallelism is said to deal with the text in terms of cohesion. Foley and Hall (2005:339) suggest that, parallelism is a cohesive one.

e.g. She is probably going to fail the exam, and she's probably going to blame her teacher. (Ibid) From all definitions above, one can observe the importance of such element in literary text and how writers employ such device to draw reader's attention towards certain elements inside the literary text. Oshima and Hogue (1999: 2) explain that parallelism is a vital apparatus in literary text, especially in representing compared or contrasted 
ideas or items. Accordingly, Waugh (1980: 64) clarifies that parallelism unify and create balances and these balances build the literary text into a unified one (Elaf \& Hussien 2020).

\section{Syntactic and Semantic Parallelism}

Cook (1989: 15) classifies three kinds of parallelism: phonological, syntactic and semantic. The focus will be on the syntactic and semantic parallelism.

- Syntactic Parallelism:

It exists when the structure of a sentence repeated the structure of another. For example

"teach us, Good Lord, to give and not to count the cost, to fight and not to heed the wounds, to toil and not to seek for rest" (Ibid)

The syntactic structure represented by Cook (1989) is recognized by Quirk and Greenbaum in (1973) as structural one. It is the likeness of two structure syntactically and lexically.

e.g. Mary likes fish. Ben prefers chicken.

The link between the two above-mentioned sentences is represented by parallelism. Both sentences have identical structures (SVO) and identical lexical components (NVN).

- Semantic Parallelism

Sematic parallelism is achieved through the repetition of different structures, phrases or words with the same meaning. For example;

A. The Good Lord, in his wisdom, has taken her away from us.

B. You mean the old girl's snuffed it.

One can notice that the meaning of the second sentence is the same with the first one, i.e., same semantic parallelism but different syntactic structures.

\section{The Analysis of Syntactic and Semantic Parallelism in Old Man and the Sea by Ernest Hemingway}

The essential direction of the paper is to draw readers' attention focusing on the functional paradigm. It is undisputable that parallelism is a mean which carry expressiveness and characterizes a concrete feature of the text. Parallelism serves as a mean to express the core textual features of a text such as integrity and unity.

\subsection{Semantic Parallelism}

Semantic parallelism is the repetition of words and phrases which are semantically related. Semantically neighboring parallelism always carries extra information. One kind of parallelism is distant repetition. This kind of repetition is used to convey new information and the lexical units separated by words or sentences

- distant lexical repetition of NOUNS: "Each line, as thick around as a big pencil, was looped onto a green-sapped stick so that any pull or touch on the bait would make the stick dip and each line had two fortyfathom coils which could be made fast to the other spare coils so that, if it were necessary, a fish could take out over three hundred fathoms of line "

- Distant lexical repetition of ADJECTIVES: "As he watched the bird dipped again slanting his wings for the dive and then swinging them wildly and ineffectually as he followed the flying fish... They are widespread and the flying fish have little chance..."

- Distant lexical repetition of VERBS: They are widespread and the flying fish have little chance. The bird has no chance"

- Distant lexical repetition of CONJUCTIONS: "He no longer dreamed of storms, nor of women, nor of great occurrences, nor of great fish, nor fights, nor contests of strength, nor of his wife"

Semantic parallelism is featured by the making of a substituted characteristic of the repeated concept. It is the most complicated kind of repetition in linguistic analysis because if expressed various kinds of repetitions. The core of this kind of repetition is the value of lexical element.

Semantic parallelism is constructed according to the repetition of synonymy, antonym, hyperhyponymy and other semantic relations. Semantic 
parallelism uses various kinds of repetitions to avoid monotonous repetition.

Synonymous repetition is used in the novel to give us the authority to expand the description.

- "The door of the house where the boy lived was unlocked and he opened it and walked in quietly with his bare feet"

The function of the expanded description in the above-mentioned example is recognized by the repetition of lexical units unlocked and opened which are used by the author. Semantic parallelism of synonymous elements is accompanied by repetition of the same lexical units most of the time. The use of synonymous elements indicates that the meaning of the two words overlaps in every aspect but their pragmatic one.

Semantic parallelism constructs on antonymy which is the contrasting meaning of lexical elements.

- "Here there were concentrations of shrimp and bait fish and sometimes schools of squid in the deepest holes and these rose close to the surface at night where all the wandering fish fed on them"

In the above example, the antonymy is the contrast of concepts realized in the lexical units, 'deepest holes' and 'surface' and identifying their opposed elements.

\subsection{Syntactic Parallelism}

Syntactic parallelism means the repetition of the same sentence structures or phrases. One of the examples of syntactic parallelism in Ernest Hemingway's Old Man and The Sea is the following:

"He rolled his trousers up to make a pillow, putting the newspaper inside them. $\underline{\boldsymbol{H e}}$ rolled himself in the blanket and slept on the other old newspapers that covered the springs of the bed"

The parallel syntactic items adopt the idea of anaphora which is the repetition of similar initial units. Accordingly, in the above-mentioned example we can notice a kind of anaphoric repetition of the constructions 'He rolled'.
" $\underline{\text { He was }}$ very fond of flying fish as they were his principal friends on the ocean. $\underline{\mathrm{He}}$ was sorry for the birds..."

This is another example of anaphoric repetition in which the repetition is achieved by the repeating of the phrases 'He was'.

There is another kind of syntactic repetition which is epiphora. It is the repetition of the same final syntactic constructions which also reinforces the intonation of the sentence.

- "They played like young cats in the dusk and he loved them as he loved the boy. He never dreamed about the boy"

There is also another type of syntactic parallelism so called polysyndenton when different kinds of conjunctions are widely used.

- "He no longer dreamed of storms, nor of women, nor of great occurrences, nor of great fish, nor fights, $\underline{\text { nor }}$ contests of strength, nor of his wife" (E. Hemingway, The Old Man and The Sea, p.13).

Another way of utilizing parallelism and to give expressiveness to the text is the absence of conjunctions which is called Asyndeton.

- "The shack was made of the tough bud shields of the royal palm which are called guano and in it there was a bed, a table, one chair, and a place on the dirt floor to cook with charcoal"

One can notice that the absence of conjunctions makes the text rich with information.

Repetition gives significant information about the emotions, expressive and style of the author. Moreover, it is an essential means of connection between sentences. Sometimes it is hard to separate the subject from the additional information, for example:

- $\quad$ They spread apart after they were out of the mouth of the harbour"

The repetition of the pronouns 'they' cannot be separated from the syntactic structure of the complex sentences. If it is separated, the sentence is going to be incomplete.

It sometimes occurs that many parallel structures can function in one sentence. For example: 
"Sometimes someone would speak in $\underline{\boldsymbol{a}}$ boat. But most of the boats were silent except for the dip of the oars".

So repetition of different kinds can be seen in the novel of Ernest Hemingway's Old Man and The Sea, for example:

- "They spread apart after they were out of the mouth of the harbour and each one headed for the part of the ocean where he hoped to find fish".

- "The old man knew he was going far out and he left the smell of the land behind and rowed out into the clean early morning smell of the ocean".

- "He saw the phosphorescence of the Gulf weed in the water as he rowed over the part of the ocean".

So according to these examples, one can find out different syntactic and lexical parallelism but the focus should be on the most organic phenomenon which the repetition - the parallelism.

Parallelism is considered as the organization and arrangement of sentences in speech or literary texts for example:

- "He simply woke, looked out the open door at the moon and unrolled his trousers and put them on. He urinated outside the shack and then went up the road to wake the boy. He was shivering with the morning cold".

The protasis is the word 'woke' and the apodosis is the infinitives; to look, unroll and put. The repetition of infinitive structures gives the text its expressivity.

\section{Conclusion}

The study of syntactic and lexical semantic parallelism in Ernest Hemingway's novel The Old Man and The Sea reaches the following conclusion:

1. The essential use of parallelism in The Old Man and The Sea contradicts the long, stable opinion which states that parallelism is a monotonous style which slow down literary works. On the contrary, it gives the narrative text an impulse that clarify the viewpoint of the writer by increasing the expressiveness and rhythm of the novel.

2. Parallelism is subject to the conscious artistic process which become the expressive mean of Hemingway's emotions and feelings.

3. Ernest Hemingway adopts anaphoric and epiphoric parallelism to create emphasis. It is used for artistic purposes to inspire, encourage and persuade readers.

4. The writer utilizes another kind of parallelism which is polysyndenton which can slow down the rhythm of the novel to make it more memorable.

5. The writer uses distant parallelism to update his/her reader's attention to the novel. It is used to create a complex bond in the structure of the novel and a mean of communication between different parts of the novel.

6. Synonymous and antonymous parallelism are used in Hemingway's novel to add emphasis. They are used to give the novel a power of persuasion to convince readers on what is true.

7. Ernest Hemingway adopts some kinds of parallelism to add color to his novel such as anaphoric, epiphoric, etc. accordingly, the aesthetic values of parallelism lie in the various employment of different kinds of stylistic devices within the context. Some types of repetition become a characteristic of Hemingway such as parallelism in the connecting structures which is widely used in modern works.

8. Hemingway's parallelism is very flexible. He can use various types of devices that reinforce the expressiveness of the text.

9. Parallelism in Hemingway's novel reflects psychological characteristics of the writer. Parallelism indicates rethinking, reflects a mixture of social and psychological features of the writer.

\section{References}


[1] Alakrash, HM, Razak, NA, \& Bustan, ES (2020). The Effectiveness Of Employing Telegram Application In Teaching Vocabulary: A Quasai Experimental Study. Multicultural Education, 6(1).

[2] Bloomfield, Morten. 1976. Stylistics and the Theory of Literature. New Literary History, Vol. 7, No. 2.

[3] Burlak, T. F., Devkin A.P., Krokhaleva L.S. 1996. Stylistics (Lexical, Syntactical and Text Levels). Minsk: Minsk State Linguistic University.

[4] Bustan, E. S., \& Alakrash, H. M. (2020). Gender Analysis Amongst Male and Female Malaysian Travelling Bloggers. International Journal of Academic Research in Business and Social Sciences, 10(6), 1-9.

[5] Chapman, R. 1973. Linguistics and Literature: An Introduction to Literary Stylistics. London; Edward Arnold

[6] Cook, G. 1989. Discourse. New York: Oxford University Press.

[7] Crystal, D. 2003. The Cambridge Encyclopedia of the English Language. Cambridge: Cambridge Edward Arnold.

[8] Elaf, B., \& Hussien, A. (2020). An analysis of impoliteness strategies performed by Donald Trump tweets addressing the middle east countries. Global journal of Social Science and Humanities, 1, 66-74.

[9] Elaf, B., \& Hussien, A. (2020). Critical Discourse Analysis of Donald Trump's Tweets Addressing the Middle Eastern Countries. International Journal of Future Generation Communication and Networking, 13(2), 26-38.

[10] Emmott C and Alexander M. 2014. Foregrounding, Burying and Plot Construction. In: Stockwell P and Whiteley $\mathrm{S}$ (eds) The Cambridge Handbook of Stylistics. Cambridge: Cambridge University Press.

[11] Folly, M. and Hall D.2005. Longman Advanced Learners Grammar. China: David Lot.
[12] Gee, J. 1999. An Introduction to Discourse Analysis. New York: Routledge.

[13] Gregoriou, Christiana. 2009. English Literary Stylistics. New York: Palgrave Macmillan.

[14] Guillen, Claudio. 1987. On the Uses of Monistic Theories: Parallelism in Poetry. New Literary History, Vol. 18, No. 3.

[15] Jakobson, R. 1960. Closing Statement: Linguistics and Poetics. In T. A. Sebeok (Ed.), Style in language Cambridge, Mass., MIT Press.

[16] Leech, G. 1977. A Linguistic Guide to English Poetry. London: Longman.

[17] Leech, G. N., \& Short, M. 2007. Style in Fiction: A linguistic introduction to English Fictional Prose. Harlow; Pearson Education Limited

[18] Lotman, Juri. 1977. The Structure of the Artistic Text. Trans. G. Lenhoff, R. Vroon. Ann Arbor: University of Michigan.

[19] Malmkjær, Kirsten. 2010. The Linguistic Encyclopedia. New York: Routledge.

[20] Matthews, P.H. 2007. Oxford Concise Dictionary of Linguistics. Oxford: Oxford University Press.

[21] Oshima, A. and A. Hogue.1999. Writing Academic English. Longman: Ryerson University Press.

[22] Quirk, R. and S. Greenbaum. 1973. A University Grammar of English. Hong Kong: Longman.

[23] Rozakis, L.(2003). English Grammar for the Utterly Confused. New York: The Mc Grown-Hill Companies.

[24] Short, M. 1996. Exploring the Language of Poems, Plays and Prose. London: Longman.

[25] Turner, G. W. 1973. Stylistics. Harmondsworth: Penguin.

[26] Wales, K. 2001. A Dictionary of stylistics. New York: Longman.

[27] Waugh, Linda R. 1980. The Poetic Function in the Theory of Roman Jakobson. Poetics Today, Vol. 2, No. 1a, pp. 
[28] Widdowson, H. G. 1975. Stylistics and The

Teaching of Literature. London: Longman

Group 